\title{
A Study on the Construction of A Diversified Environmental Audit Work Pattern
}

\author{
Xianhua $\mathrm{Wu}^{1}$, Lianxi Wang ${ }^{2}$, Hong Chen $^{1}$ \\ ${ }^{1}$ Yuxi Research Center for Eco- environmental Sciences on Plateau Lakes, Yuxi Normal University, \\ Yuxi Yunnan, 653100, China \\ ${ }^{2}$ Yunnan Provincial Audit Office, Kunming Yunnan, 653100, China
}

Keywords: Diversified environment, Audit work, Pattern.

\begin{abstract}
In the process of execution, various problems will be encountered in audit work as well, and in order to solve these problems, the multi-pattern development of audit work must be realized. The construction of a diversified environmental audit work pattern can not only improve the ideological consciousness of the staff, but also promote the optimized integration of the internal structure of organs in China to increase the implementation efficiency of audit work, thus providing effective countermeasures for China's economic development and ecological civilization construction. Therefore, this paper analyzes the main purpose of the construction of a diversified environmental audit work pattern as well as the problems needing attention during the construction and then gives effective advice on these problems.
\end{abstract}

\section{Introduction}

Audit institutions should make full use of internal and external resources for an audit of work in all aspects in the diversified environmental audit work. In addition, audit institutions should pay attention to resource conservation and environmental protection during the actual audit, and realize the associated development of resource audit and other audit work according to China's economic structure and actual situation in order to promote the diversified development of environmental audit.

\section{Purpose of the Construction of A Diversified Environmental Audit Work Pattern}

The purpose of the construction of a diversified environmental audit work pattern is mainly reflected in four aspects, and the formation of construction work is of great significance.

Firstly, the construction of a diversified environmental audit work pattern can promote the optimized formation of an audit immune system. As audit work refers to the immune system of international economic development in essence, audit work responsibilities include preventing the immune system and playing a good defense role. For the establishment of a diversified development pattern of environmental audit, it is necessary to promote the coordinated development of the work, and ensure the coordinated application of the work. In the period, not only should the environmental protection department vigorously implement the work, but also unified collaboration of various departments is required. A diversified environmental audit pattern can maintain national resources and realize the security development of ecological environment, which can not only safeguard people's life and property, but also promote the sustainable construction of Chinese economy. As a result, the immune system function of national economy should be given full play to.

Secondly, the construction of a diversified environmental audit work pattern can promote the constant expansion and extension of audit work, and provide an effective guarantee for the work. With the continuous improvement of modern social and economic level, the government audit 
department has to face a larger difficulty in work execution. In the process of work execution, the most important function of the traditional government audit department is to implement supervision of economic construction work, but in modern social development, the audit department should form a number of job functions to mainly realize the work including evaluation, management, and service. For the active development of environmental audit work, it is necessary to clarify laws and regulations as well as policy standards, and conduct rational management and effective supervision of environmental activities, environmental financial information and management system within units according to the current environmental development needs in China. The implementation of the work is the highest requirement formed during the work execution of the audit department. Therefore, during the work execution, the audit department should take auditing standards as a powerful implementation basis, and conduct systematic evaluation and supervision of various units on a regular basis. Only in this way, can the environmental audit work be actively implemented, and the effective extension and expansion of the work be promoted.

Thirdly, the construction of a diversified environmental audit work pattern can form a perfect resource system and promote the formation of resultant force. In the current stage of development, environmental problems have always been a topic of general concern to the whole society, especially in all aspects of people's life. Therefore, solutions to the existing problems must be found out during the execution and audit of the work. Under normal circumstances, the existing problems in audit work mainly include a broad scope of audit, as well as high requirements of complex and diverse industries, policies and majors. In order to promote the strict implementation of audit work and the effective development of the work, it is necessary to make an integrated use of the internal resources and external resources of the audit department and organize the mutual cooperation between financial auditors and investment auditors so that each audit work link can be effectively executed. Moreover, attention should be paid to the relevant problems existing in the environmental protection work, and an analysis should be made of a waste of resources as well as environmental pollution in the work process to reduce the harm of these problems to people's life and property, ensuring that all aspects of environmental audit can be gathered together to form a powerful force. In this way, an effective audit supervision pattern can be formed and the perfection of environmental audit can be promoted.

\section{Problems Needing Attention during the Construction of A Diversified Environmental Audit Work Pattern}

\section{Diversification of Scheduling}

In the environmental audit work, the first step is to develop a relevant implementation plan. Now China is in the development stage of planned economy, so a relevant plan must be developed to ensure that the plan can be fully implemented. In the specific implementation process, it is necessary to realize the all-round investigation and research work, promote the stringency and rationality of environmental audit work, and achieve the coordination and stability of planned compiling work so as to ensure the scientificity formed of the planned appraisal system, thus facilitating the formation of the next plan $^{[1]}$.

\section{Diversification of Department Involvement}

Environmental protection has been a topic of concern in China. During the design of this topic, all aspects of social economy should be taken into consideration. Therefore, not only should environmental protection be taken as a main factor of implementation by the country and government, but also efforts should be made by each of us. The most critical step is to enhance people's awareness of environmental protection, and establish an effective implementation strategy for the environment construction and sustainable development of society. Meanwhile, the department should realize financial audit, investment audit and other aspects during the audit to ensure that various units can take active participation to achieve the diversified development of environmental audit pattern. 


\section{Diversification of Audit Contents}

Audit contents must be more fully formed in line with the main strategic needs of modern scientific outlook on development. For financial audit, environmental protection policy and fund utilization are taken as the main implementation contents to promote the effective formation of construction goal and achieve the associated development of financial audit and environmental audit. In this way, environmental audit can be taken as the main implementation content. For banking audit, the national environmental protection policy is mainly taken as the main basis, and punishment should be given to high-consumption and high-pollution industries during the execution. Therefore, enterprises should combine environmental audit and enterprise audit in the audit process, change the existing problems in the industrial structure, and achieve a certain environmental protection purpose. For foreign capital audit, an audit should be conducted for each link of environmental project as well as various existing problems.

\section{Diversification of Technical Methods}

In the environmental audit, the sustainable development strategy should be fully implemented, and economic growth, environmental protection and social development should be taken as the main factors. During the optimization and perfection of environmental protection work, it is necessary to first realize the environmental problems in China, and then make an active exploration to find the main methods of technical optimization. However, China's environmental audit has a small scope of audit and a lack of rich audit experience in the whole implementation process of the work. Therefore, a scientific and perfect environmental audit system should be established to promote the formation of a diversified and modern pattern and make use of new modern techniques and methods, thereby ensuring the optimized development of audit work in China.

\section{Diversification of Result Application}

For the execution of environmental audit work, audit work should be converted into results and applications to ensure that social resource conservation and environmental protection can be taken as the main contents. Therefore, audit results should be given full play to and a diversified audit pattern should be established in the process of execution. In the audit work, various departments should establish a cooperation mechanism, clarify work responsibilities, realize the innovative development of audit ideas, and effectively expand audit results ${ }^{[2]}$.

\section{Main Methods for the Construction of A Diversified Environmental Audit Work Pattern}

For the relevant problems above, effective implementation views should be formed to build a diversified environmental audit work pattern, and promote the optimized development of environment in China. In the process of work execution, it is necessary to form a correct understanding of the work, clarify main tasks in the work, establish a perfect implementation system, strengthen the strict implementation by the audit team, and promote the optimized integration of resources, thus ensuring the realization of sustainable construction of diversified environmental audit.

\section{Formation of Understanding}

To improve the understanding of diversified environmental audit should be completed in two ways. Firstly, a new development concept should be built, and particularly, a comprehensive understanding of diversified environmental audit work should be formed. The diversification of internal audit work must be promoted to make diversified environmental audit conform to the development trend of modern social development. Environmental audit is a leap-forward pattern of modern social development. To promote the depth of environmental audit contents and ensure the enrichment of these contents can not only realize the innovative development of audit work, but also form all-round sustainable development construction for China's social and economic development. Secondly, a new understanding of environmental audit work should be formed in the development of a new social environment. In order to achieve the all-round and sustainable development of environmental audit 
work, and promote the formation of a resource-saving and environment-friendly society, everyone should realize that it is necessary to achieve the harmonious development between man and nature so as to promote the all-round execution of environmental audit work ${ }^{[3]}$.

\section{Definition of Task}

To clarify the tasks for the implementation of environmental audit work, a rational implementation plan should be developed at first in the specific implementation period to promote the effectiveness and scientificity of execution of work tasks. Moreover, various governments should coordinate the tasks, realize the scientific planning of the work, and promote the comprehensive development of environmental audit work. For the current project in construction, the professional supervision and management of the work must be guaranteed so that an all-round audit can be realized. Secondly, it is necessary to strictly grasp audit contents, and combined with audit contents and in accordance with the relevant implementation standards, implement the program developed by audit institutions, thus ensuring the realization of environmental protection audit in the whole process.

\section{Perfection of System}

To reinforce the construction of an environmental audit coordination mechanism should be completed in two ways in the specific implementation process. Firstly, a relevant mechanism should be established for the environmental audit department, and various governments should establish an environmental audit mechanism and a leadership coordination mechanism in line with the actual situation for units. According to the local actual development situation, it is necessary to promote the scientificity and rationality of audit planning formulation, form the annual environmental audit work plan, and organize and lead the execution of environmental audit work. In addition, it is required to pay attention to each audit department, analyze various existing problems during the work of audit department, give relevant execution experience for the problems, and promote the effective execution of work sharing. Secondly, the government and various departments should strengthen coordination and management because the environmental audit work cannot be completed independently by one department but it requires the mutual cooperation among various departments. Therefore, audit institutions should regularly check contents in all aspects such as environmental protection, territorial resources and forestry, hold regular implementation meetings for various departments, and integrate contents in all aspects, thus ensuring the perfectness of environmental audit plan formulation as well as the strict implementation of environmental audit work ${ }^{[4]}$.

\section{Integration of Resources}

Various resources existing in the environmental audit work should be integrated. In the process of execution, on the one hand, environmental auditors should be integrated, and for the internal staff of audit department, some professional and technical talents should be arranged in various positions in accordance with the relevant requirements in documents. Moreover, some talents in computer and engineering management should be employed in the environmental audit work, and meanwhile, some experts in environmental protection and resource protection should be employed to build a perfect environmental resource database so that the staff can effectively complete the environmental audit work through guidance. On the other hand, various resources and information in the environmental audit work should be integrated, audit resources and information in all aspects should be integrated, and the same information should be classified. Then the existing problems should be promptly reported to the relevant department in order to ensure that a good solution can be given according to the relevant experience during the work execution. In this case, not only can the role of audit work be played, but also the perfection of various systems can be promoted ${ }^{[5]}$.

\section{Perfection of Team}

Several measures should be taken to perfect the environmental audit talent team. Firstly, training should be given to the environmental audit talent team so that talents can grasp sufficient theoretical knowledge. The theoretical knowledge content of environmental audit is more extensive, so auditors 
should master contents in all aspects such as economy, management, and engineering, and grasp knowledge as well as skills. Meanwhile, audit institutions should reinforce the training of theoretical and practical knowledge for talent team, constantly expand the development vision of the staff, and improve the practical ability of the staff. Moreover, talents should be introduced in the practice of environmental audit since rational implementation standards can be formed only in practice. Secondly, the government should regularly organize the staff to participate in the training, and based on the expansion of their vision, improve their work ability. Furthermore, the exchanges and communication with the international community should be strengthened, and foreign advanced experience should be absorbed to form international standards for own construction team. Finally, a summary and analysis should be made of the experience in diversified environmental audit, and in this period, each auditor should be asked to draw on the relevant experience in practice and fully learn the theoretical knowledge of audit to promote the good implementation of propaganda work, thus forming a diversified environmental audit work system and promoting the optimization of its utilization.

\section{Conclusion}

In the course of future development, a diversified environmental audit work pattern will become the mainstream of development in the society and can promote the steady construction of social economy. Therefore, in order to realize the diversification of environmental audit work, audit institutions should not only clarify work tasks and determine the main development direction, but also enhance environmental resources and talent team construction, thereby ensuring the formation of a new diversified environmental audit work pattern.

\section{Acknowledgement}

This paper is supported by the Yunnan College Science and Technology Innovation Team Support Program Funding (IRTSTYN201422).

\section{References}

[1] Yan Xiaoyuan. A Study on the Construction of A Diversified Environmental Audit Work Pattern, Business, 2015 (22): 142-142.

[2] Huang Daoguo and Shao Yunfan. A Study on the Construction of A Diversified Environmental Audit Work Pattern, Auditing Research, 2011 (3): 31-35, 41.

[3] Wang Weiya and $\mathrm{Wu}$ Zhouping. Considerations on the Construction of A Diversified Environmental Audit Work Pattern, Auditing and Finance, 2010 (7): 9-10.

[4] Meng Zhihua. A Study on the Construction of A Diversified Environmental Audit Work Pattern, Journal of Hubei University of Economics (Humanities and Social Sciences), 2016, 13 (9): 90-91.

[5] Cong Youxin. An Exploration into the Ways of Implementation of Enterprise Follow-up Auditing Work under the Goal of Diversification, Modern Business, 2012(14): 212-212. 